\title{
Flexible graphite film with laser drilling pores as novel integrated anode free of metal current collector for sodium ion battery
}

\author{
Pengxian Han ${ }^{\text {a, } 1}$, Xiaoqi Han ${ }^{\text {a,b, } 1}$, Jianhua Yao ${ }^{\text {a }}$, Zhihong Liu ${ }^{\mathrm{b}}$, Xiaoyan Cao ${ }^{\mathrm{b}}$, Guanglei Cui ${ }^{\mathrm{a}, *}$

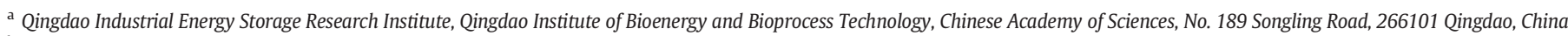 \\ ${ }^{\mathrm{b}}$ Key Laboratory of Marine Chemistry Theory and Technology, Ministry of Education; College of Chemistry and Chemical Engineering, Ocean University of China, Qingdao 266100, China
}

\section{A R T I C L E I N F O}

\section{Article history:}

Received 24 September 2015

Received in revised form 16 October 2015

Accepted 16 October 2015

Available online 23 October 2015

\section{Keywords:}

Porous graphite film

Laser drilling pores

Anode

Sodium ion battery

Co-intercalation

\begin{abstract}
A B S T R A C T
In this work, flexible polyimide graphite films with laser drilling pores were prepared by laser drilling pore technique. Then a full cell was built based on the porous graphite film anode, $\mathrm{Na}_{3} \mathrm{~V}_{2}\left(\mathrm{PO}_{4}\right)_{3}$ cathode, and $\mathrm{NaPF}_{6}$ in diglyme electrolyte. This unique battery system makes the best of co-intercalation mechanism of $\mathrm{Na}^{+}$-solvent into porous graphite film host. Moreover, the porous graphite film is directly served as an integrated anode with no electrochemically inactive components, such as binders, conductive agents and metallic current collectors. The above merits allow remarkable progress in electrochemical performance, especially the high energy density and much improved cycle life, which will significantly boost the high energy batteries. Our sodium-ion system is potentially promising power sources for promoting the substantial use of low-cost energy storage systems.
\end{abstract}

(C) 2015 Elsevier B.V. All rights reserved.

\section{Introduction}

Over the past few decades, lithium-ion batteries (LIBs), by virtue of their high energy density and long cycle life, have been widely applied in portable electronic devices, electric vehicles and large-scale electrical energy storage systems [1-3]. However, for further development of LIBs, one of serious challenges still to be solved is the high cost of limited lithium resources [4]. Therefore, development of novel electrochemical storage devices is not only desirable but also necessary. In this background, sodium-ion batteries (NIBs) are regarded as a promising alternative since sodium is considered as natural abundance. Moreover, Li and Na share similar physical and chemical properties as alkali metals [5]. The remarkable cost-effective advantage endows the NIBs with great potentials in renewable energy fields.

The exploration of anode materials for NIBs started with carbonaceous materials, such as graphitic carbon and non-graphitic carbon materials [6-11]. It was generally considered that graphite anode, commonly used in LIB systems, could barely intercalate sodium in common electrolyte systems by forming binary graphite intercalation compounds ( $b$-GICs), because sodium ions are too large to insert into the graphite interlayers $[12,13]$. Fortunately, the situation changed when Adelhelm's group found that sodium can be reversibly intercalated into artificial graphite by taking advantage of co-intercalation mechanism in the form of ternary graphite intercalation compounds ( $t$-GICs)

\footnotetext{
* Corresponding author. Tel.: + 86532 80662746; fax: + 8653280662744

E-mail address: cuigl@qibebt.ac.cn (G. Cui).

1 Pengxian Han and Xiaoqi Han contributed equally to this work.
}

in a diglyme-based electrolyte, which milestone graphite materials towards anode of NIBs [14]. More recently, Kang's group also investigated the $\mathrm{Na}^{+}$-solvent co-intercalation combined with partial pseudocapacitive behaviors in natural graphite [15]. However, the capacity retention and the energy density of the full cell should be further promoted.

Flexible polyimide graphite films possess a highly in-plane oriented structure [16], which endows the graphite film with excellent planar electrical conductivity and considerable mechanical strength. By laser drilling pores on the graphite films, more intercalation channels were obtained to improve the kinetics. In comparison with conventional multicomponent electrodes that are coated on current collector forming a mixture of binder and active material, a porous graphite film anode with no binder, conductive agents and current collector could improve the energy density and simplify the production process of a full cell [17]. Besides, a porous graphite film anode can also enlarge the contact area with electrolyte which might be favorable for co-intercalation process. To the best of our knowledge, a novel NIB full cell consisting of a porous graphite film anode and a $\mathrm{Na}_{3} \mathrm{~V}_{2}\left(\mathrm{PO}_{4}\right)_{3}$ cathode in diglyme-based electrolyte, which exhibits much improved energy density and prolonged cycling behavior, has not been reported previously in the literature. Therefore, it is fundamentally significant to develop such a novel NIB anode system. We expect that it would strike a chord and make a contribution to the cost-effective and environmentally friendly NIBs.

\section{Experimental}

The Kapton-type polyimide films of $50 \mu \mathrm{m}$ thickness manufactured by Dupont Co., Ltd. were used as starting materials. They were 
carbonized step by step at 600,1600 and $2200{ }^{\circ} \mathrm{C}$, respectively. Then the carbonized films were further graphitized at $2800{ }^{\circ} \mathrm{C}$ for $3 \mathrm{~h}$ in an argon atmosphere, by being sandwiched between polished graphite plates. After graphitization, the graphite films were pressed to obtain $30 \mu \mathrm{m}$ thickness. Pores of $50 \mu \mathrm{m}$ in diameter were obtained by laser drilling technique (YLP-1-100-20-20, IPG (Beijing) Fiber Laser Technology Co., Ltd.). The distance between the pores was $240 \mu \mathrm{m}$. The depth of pores is also $30 \mu \mathrm{m}$ and can be controlled.

The $\mathrm{Na}_{3} \mathrm{~V}_{2}\left(\mathrm{PO}_{4}\right)_{3}$ powders was synthesized according to previously reported literature [18]. Typically, $\mathrm{NaCO}_{3}, \mathrm{NH}_{4} \mathrm{H}_{2} \mathrm{PO}_{4}, \mathrm{~V}_{2} \mathrm{O}_{5}$ and glucose were firstly mixed in stoichiometric ratio and preheated at $400{ }^{\circ} \mathrm{C}$ for $6 \mathrm{~h}$. Then, the mixture was further heated at $800{ }^{\circ} \mathrm{C}$ in $\mathrm{Ar}$ atmosphere for $12 \mathrm{~h}$. Excess glucose was added in order to obtain absolutely pure $\mathrm{Na}_{3} \mathrm{~V}_{2}\left(\mathrm{PO}_{4}\right)_{3}$ product.

The porous graphite films were punched into $10 \mathrm{~mm}$ diameter disc electrode and used as anode directly. The mass was $3 \mathrm{mg}$. The cathode was prepared by mixing $\mathrm{Na}_{3} \mathrm{~V}_{2}\left(\mathrm{PO}_{4}\right)_{3}(80 \mathrm{wt}$.\%) with polyvinylidene fluoride binder (10 wt.\%) and conductive carbon black (10 wt.\%) in $\mathrm{N}$-methyl-2-pyrrolidone solvent. Then the slurry was pasted onto an aluminum foil followed by drying in vacuum at $120^{\circ} \mathrm{C}$ for $2 \mathrm{~h}$. After roll-pressing, $10 \mathrm{~mm}$ diameter disc electrodes were punched. The loading mass of the active material on the electrode was $2.4 \mathrm{mg}$. A Teflon Swagelok ${ }^{\circledR}$ type test cell was assembled with a sodium metal counter electrode and a glassy fibrous separator in Argon-filled glove-box. Similarly, the full cell was fabricated using a porous graphite film anode and $\mathrm{Na}_{3} \mathrm{~V}_{2}\left(\mathrm{PO}_{4}\right)_{3}$ cathode. All the electrochemical performances were tested in $1 \mathrm{M} \mathrm{NaPF}_{6}$ in diglyme electrolyte. The $\mathrm{H}_{2} \mathrm{O}$ content in the electrolyte is $<20 \mathrm{ppm}$. Before assembling the cells, the $\mathrm{NaPF}_{6}$ salt was maintained in a vacuum oven at $180{ }^{\circ} \mathrm{C}$ for $72 \mathrm{~h}$. Cycle voltammetry (CV) of the cells was performed on an electrochemical workstation (ZAHNER-Elektrik GmbH \& Co. KG, Germany). Galvanostatic charge and discharge behaviors were tested on a battery testing system (Wuhan LAND electronics Co., Ltd., China). Morphological and structural information was obtained from field emission scanning electron microscopy (SEM, HITACHI S-4800) and high-resolution transmission electron microscopy (HRTEM, JEOL 2100F). X-ray diffraction (XRD) patterns were recorded in a Bruker-AXS Micro-diffractometer (D8 ADVANCE) with $\mathrm{Cu} K \alpha$ radiation $(\lambda=1.5406 \mathrm{~nm}$ ).

\section{Results and discussion}

Fig. 1 demonstrates the XRD patterns and SEM images of the graphite film and $\mathrm{Na}_{3} \mathrm{~V}_{2}\left(\mathrm{PO}_{4}\right)_{3}$ powder. As shown in Fig. $1 \mathrm{a}$, the sharp and strong peak around $2 \theta=26.5^{\circ}$ is typical of layered graphite structure. The HRTEM image gives a more direct evidence of highly in-plane oriented structure (the inset in Fig. 1a). The parallel basal planes are well stacked with an average distance of $0.3355 \mathrm{~nm}$. In order to increase the intercalation channels of the sodium ions, the uniform and orderly pores with diameter of $50 \mu \mathrm{m}$ are obtained by laser drilling technique on the surface of the graphite films, as can be seen in Fig. 1b. All diffraction peaks of $\mathrm{Na}_{3} \mathrm{~V}_{2}\left(\mathrm{PO}_{4}\right)_{3}$ powders are in good agreement with the NASICON framework (Fig. 1c), which can be well in agreement with the typical XRD patterns of $\mathrm{Na}_{3} \mathrm{~V}_{2}\left(\mathrm{PO}_{4}\right)_{3}$ powders with no peaks of any other phases or impurities [19]. Fig. 1 suggests that the micro or nano sized particles could be favorable for ion diffusion because the transport length and the chemical diffusion resistance are decreased [20].

The electrochemical properties of the porous graphite film and $\mathrm{Na}_{3} \mathrm{~V}_{2}\left(\mathrm{PO}_{4}\right)_{3}$ electrodes against $\mathrm{Na}$ metal were evaluated in $1 \mathrm{M}$ $\mathrm{NaPF}_{6} /$ diglyme electrolyte. Fig. 2a, shows the CV curves of the graphite film with and without drilling pores. Obviously, the graphite film without drilling pores exhibits negligible electrochemical activity. Interestingly, when the drilling pores are formed on graphite films, which provide a large number of electrochemical active sites, reversible sodium ion intercalation/deintercalation peaks are observed, showing similar electrochemical behaviors with natural or artificial graphite electrode in the same electrolyte [14,15]. The charge/discharge profiles deliver a reversible capacity of $127.1 \mathrm{mAh} \mathrm{g}^{-1}$ (Fig. 2b). Interestingly,
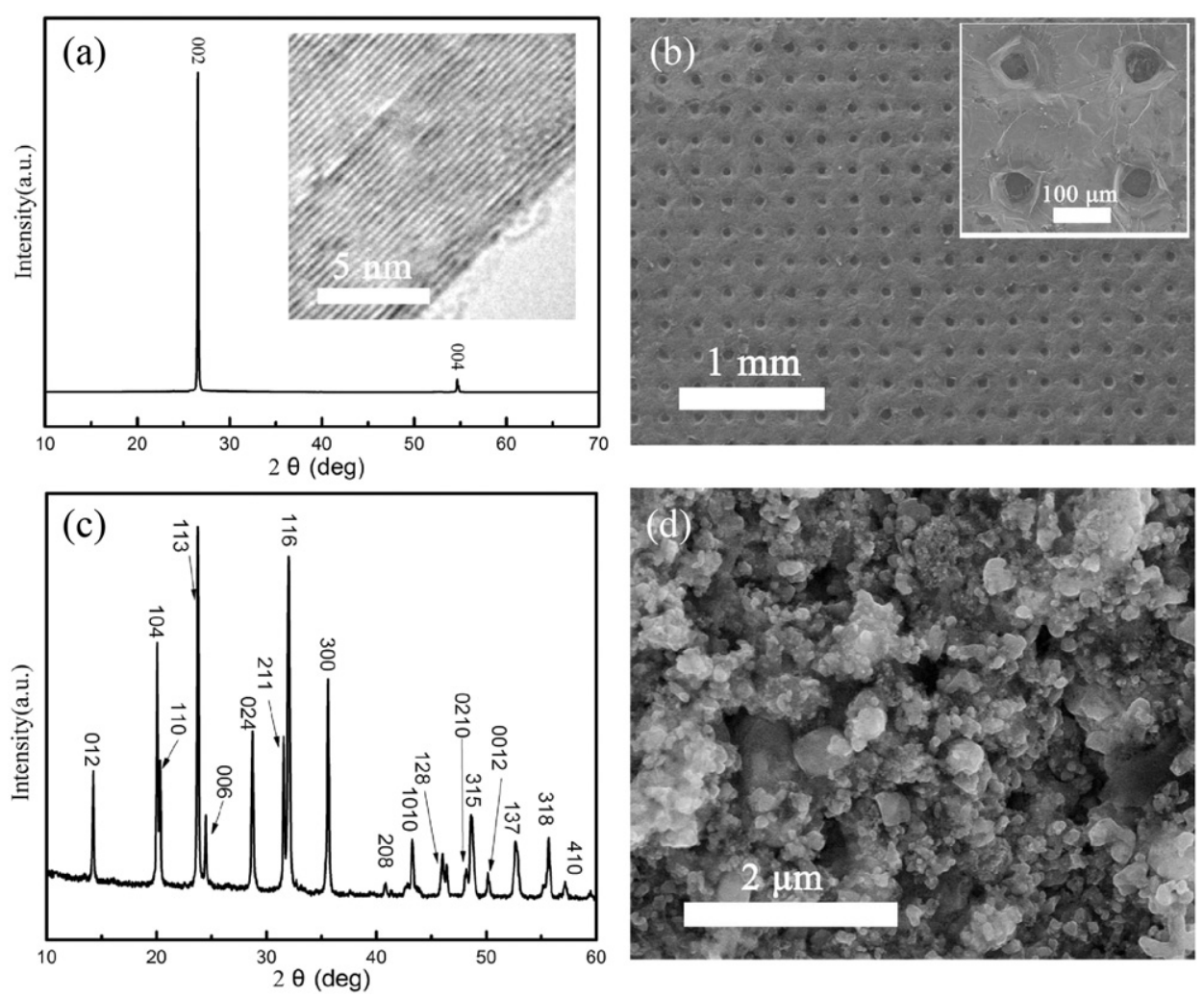

Fig. 1. (a) Typical XRD pattern and (b) SEM images of the porous graphite film, the inset in (a) is its HRTEM; (c) XRD pattern and (d) $S E M$ image of $\mathrm{Na}_{3} \mathrm{~V}_{2}\left(\mathrm{PO} \mathrm{O}_{4}\right)_{3}$ powder. 

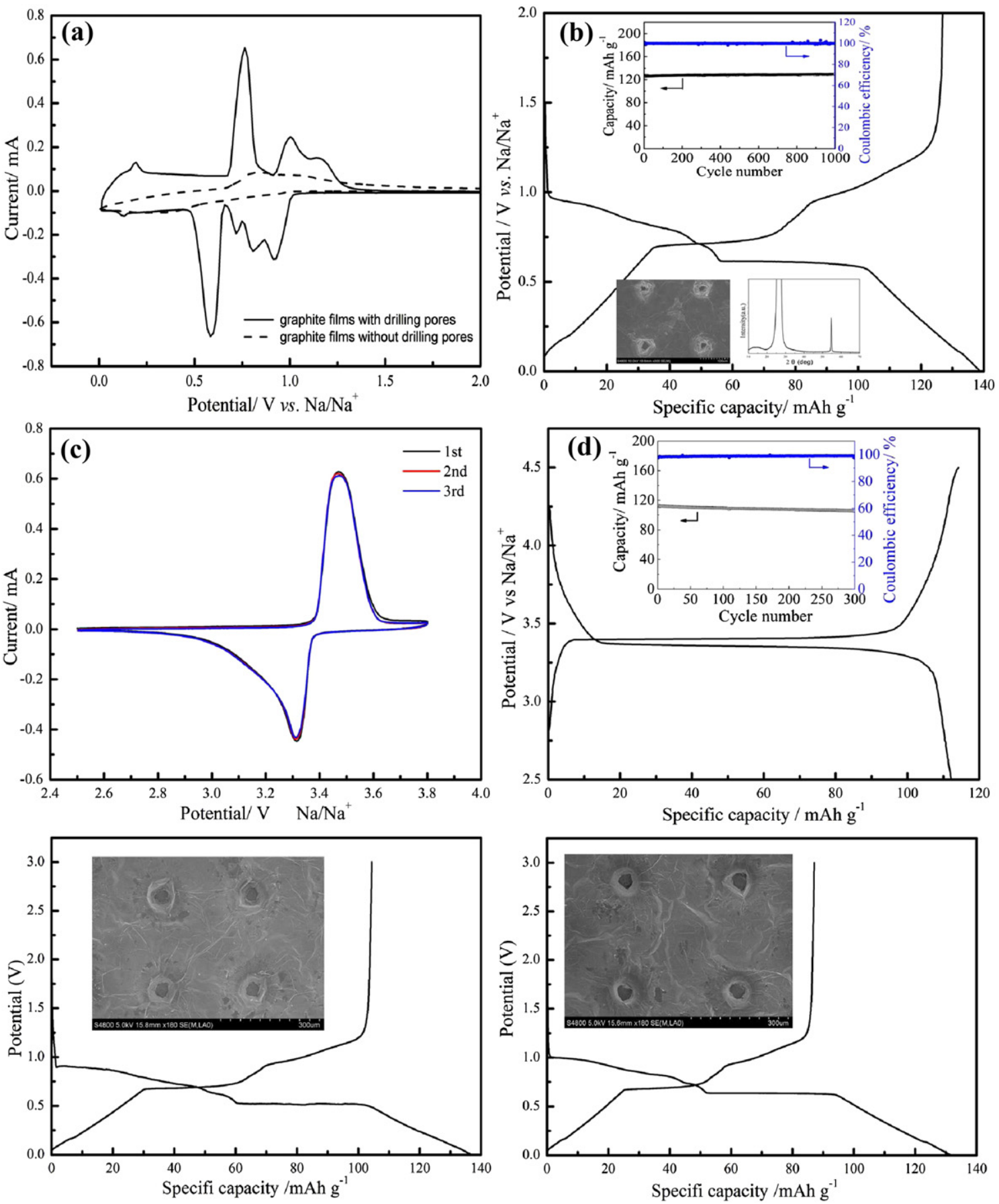

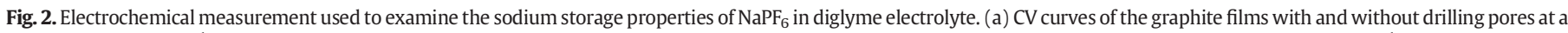

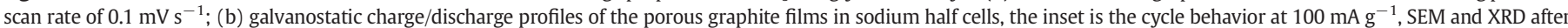

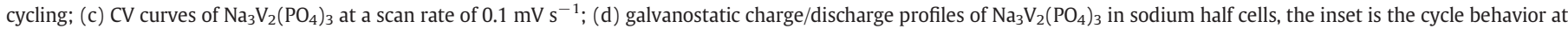
$100 \mathrm{~mA} \mathrm{~g}^{-1}$; charge/discharge curves of the graphite film with pore distance of (c) 280 and (d) $320 \mu \mathrm{m}$, the insets are their SEM images.

even after 1000 cycles at $100 \mathrm{~mA} \mathrm{~g}^{-1}$, there is hardly any capacity decay. The coulombic efficiency is as high as $99.9 \%$. It can be clearly seen from the inset in Fig. 2b that the pores on the graphite film are well kept in circle with no obvious crack or exfoliation after cycling, and the 002 diffraction peak after full reduction is recovered to the original state. This further confirms that the co-intercalation reaction of sodium ions with solvent into the host of the porous graphite films is highly reversible. The CV curve of the first three cycles for the $\mathrm{Na}_{3} \mathrm{~V}_{2}\left(\mathrm{PO}_{4}\right)_{3}$ electrode is displayed in Fig. 2c in the potential range of $2.5-3.8 \mathrm{~V} \mathrm{vs}$. Na ${ }^{+} / \mathrm{Na}$ at a scanning rate of $0.1 \mathrm{mV} \mathrm{s}^{-1}$. The sodium ion deintercalation/intercalation peaks are located at 3.5 and 3.3 $\mathrm{V} \mathrm{vs.} \mathrm{Na}^{+} / \mathrm{Na}$, respectively [21-23]. The obvious flat voltage plateau is observed at $3.4 \mathrm{~V} \mathrm{vs}$. $\mathrm{Na}^{+} / \mathrm{Na}$ in the charge/discharge curves (Fig. 2d). The $\mathrm{Na}_{3} \mathrm{~V}_{2}\left(\mathrm{PO}_{4}\right)_{3}$ electrode delivers initial charge capacity of $114.2 \mathrm{mAh} \mathrm{g}^{-1}$ and discharge capacity of $112.3 \mathrm{mAh} \mathrm{g}^{-1}$, and the initial coulombic efficiency is $98.3 \%$, which is superior to the common ester-based electrolyte [14]. Encouragingly, a satisfactory capacity retention of $93.4 \%$ is obtained after 300 cycles at $100 \mathrm{~mA} \mathrm{~g}^{-1}$. To further investigate the effect of drilled pores on the electrochemical performance, two samples with different pore distance were prepared, as shown in Fig. 2e and f. It is interestingly found that the reversible specific capacities of the graphite film with pore distance of 280 and 

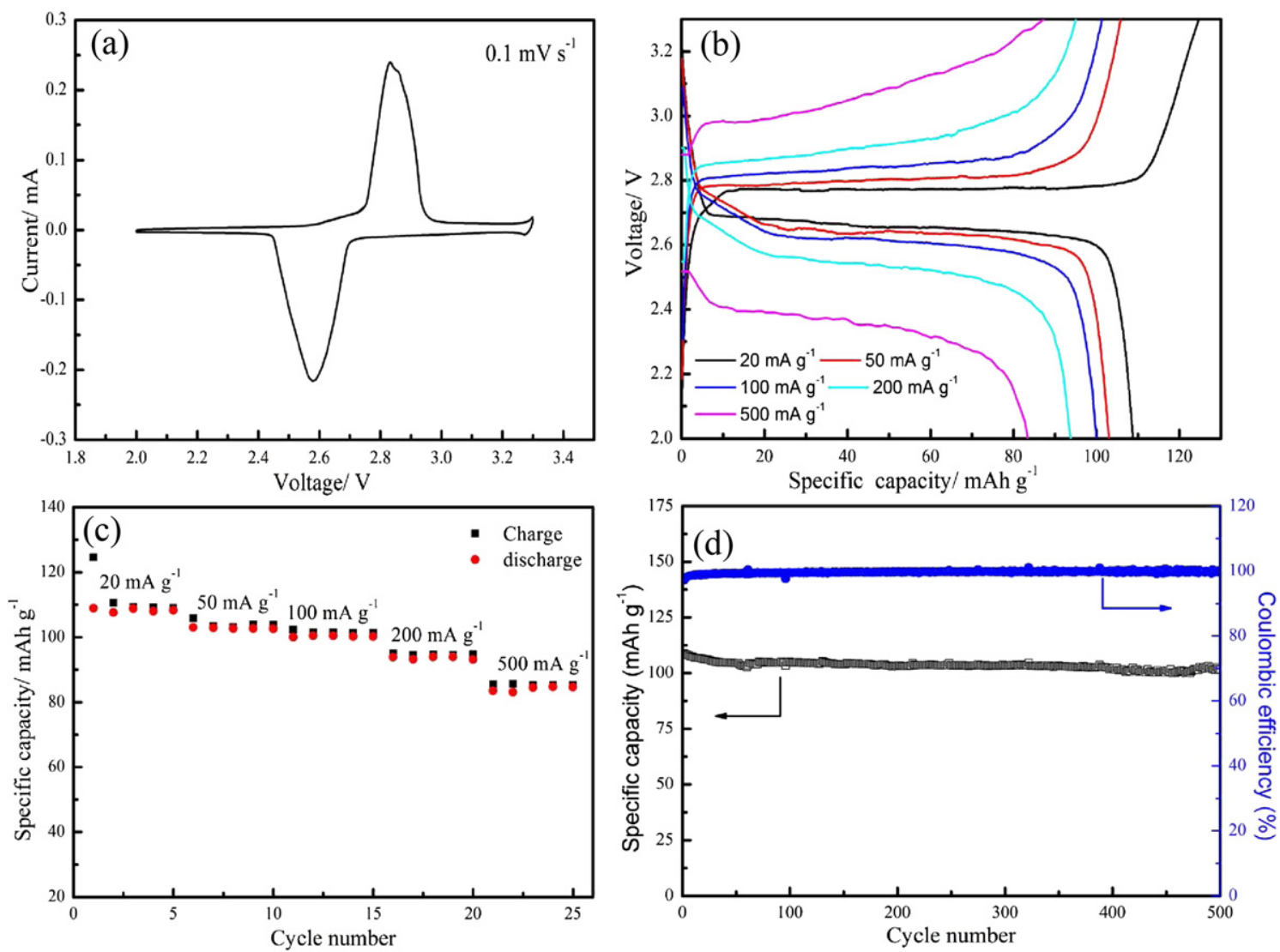

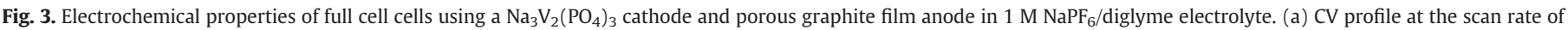
$0.1 \mathrm{mV} \mathrm{s}^{-1}$; (b) charge/discharge curves at varied current densities; (c) rate capability; (d) cycle performance at current density of $100 \mathrm{~mA} \mathrm{~g}{ }^{-1}$.

$320 \mu \mathrm{m}$ are 104.4 and $87.1 \mathrm{mAh} \mathrm{g}^{-1}$, respectively, which indicates that there exists an effective ion diffusion distance. The distance between the pores influence the ion intercalation capacity.

The full cell was assembled with porous graphite film anode and $\mathrm{Na}_{3} \mathrm{~V}_{2}\left(\mathrm{PO}_{4}\right)_{3}$ cathode in $1 \mathrm{M} \mathrm{NaPF}_{6} /$ diglyme electrolyte. CV curve of the NIBs between 2.0 and $3.3 \mathrm{~V}$ at a scan rate of $0.1 \mathrm{mV} \mathrm{s}^{-1}$ is shown in Fig. 3a. Two peaks located at 2.9 and $2.5 \mathrm{~V}$ are observed, corresponding to the charge and discharge process, respectively. Similarly, two flat charge/discharge plateaus are also presented at 2.92 and $2.54 \mathrm{~V}$ under the current density of $200 \mathrm{~mA} \mathrm{~g}^{-1}$ (Fig. 3b). The initial charge and discharge capacity is $124.6 \mathrm{mAh} \mathrm{g}^{-1}$ and $108.9 \mathrm{mAh} \mathrm{g}^{-1}$ based on the cathode active material, respectively, with an initial coulombic efficiency of $87.4 \%$ at $20 \mathrm{~mA} \mathrm{~g}^{-1}$. Even at an increased current density of $500 \mathrm{~mA} \mathrm{~g}^{-1}$, the discharge capacity remains $83.5 \mathrm{mAh} \mathrm{g}^{-1}$, indicative of outstanding rate capability. The energy density of such NIBs system is $130.7 \mathrm{Wh} \mathrm{kg}^{-1}$ based on the total electrode materials, which is superior to the NIB system with natural graphite anode and $\mathrm{Na}_{1.5} \mathrm{VPO}_{4.8} \mathrm{~F}_{0.7}$ cathode in the same electrolyte (120 $\mathrm{Wh} \mathrm{kg}^{-1}$ based on the electroactive materials) [15]. Moreover, even after 500 cycles, a desired capacity retention of $92.0 \%$ is retained at $100 \mathrm{~mA} \mathrm{~g}^{-1}$. Therefore, the porous graphite film could be potentially served as anode of NIBs owing to the excellent electrochemical performance in diglyme-based electrolyte by virtue of co-intercalation mechanisms.

\section{Conclusions}

By using laser drilling technique, a novel porous graphite film for an integrated anode of NIBs was explored, which delivered a reversible capacity of $127.1 \mathrm{mAh} \mathrm{g}^{-1}$ with a good cycle performance for 1000 cycles, using $\mathrm{Na}^{+}$-solvent co-intercalation mechanism in diglyme-based electrolyte. When it is assembled with $\mathrm{Na}_{3} \mathrm{~V}_{2}\left(\mathrm{PO}_{4}\right)_{3}$ cathode, a NIB full cell was presented with an energy density of $130.7 \mathrm{Wh} \mathrm{kg}^{-1}$. Encouragingly, even after 500 cycles, a satisfactory capacity retention of $92.0 \%$ was retained. It is worth mentioning that the porous graphite film was directly used as an integrated anode without any other inactive components, which could further enhance the cell energy density and simplify the fabrication process. Above all, the new design of such an advanced NIB system provides a promising direction for sustainable energy storage systems and offers a possibility in practical application.

\section{Acknowledgments}

This work was supported by the Key Research Program of the Chinese Academy of Sciences (Grant No. KGZD-EW-202-2), National Natural Science Foundation of China $(21271180,21401208)$, the National High Technology Research and Development Program of China (863 Program, No. 2013AA050905), the Key Technology Research Projects of Qingdao (No. 13-4-1-10-gx), and the Qingdao Key Lab of solar energy utilization and energy storage technology.

\section{References}

[1] J.-M. Tarascon, M. Armand, Issues and challenges facing rechargeable lithium batteries, Nature 414 (2001) 359-367.

[2] N.A. Kaskhedikar, J. Maier, Lithium storage in carbon nanostructures, Adv. Mater. 21 (2009) 2664-2680.

[3] S. Xin, Y.-G. Guo, L.-J. Wan, Nanocarbon networks for advanced rechargeable lithium batteries, Acc. Chem. Res. 45 (2012) 1759-1769.

[4] H. Pan, Y.-S. Hu, L. Chen, Room-temperature stationary sodium-ion batteries for large-scale electric energy storage, Energy Environ. Sci. 6 (2013) 2338-2360.

[5] V. Palomares, P. Serras, I. Villaluenga, K.B. Hueso, J. Carretero-González, T. Rojo, $\mathrm{Na}$-ion batteries, recent advances and present challenges to become low cost energy storage systems, Energy Environ. Sci. 5 (2012) 5884-5901.

[6] Y. Wen, K. He, Y. Zhu, F. Han, Y. Xu, I. Matsuda, Y. Ishii, J. Cumings, C. Wang, Expanded graphite as superior anode for sodium-ion batteries, Nat. Commun. 5 (2014) 4033. 
[7] R. Alcántara, F.J. Fernández Madrigal, P. Lavela, J.L. Tirado, J.M. Jiménez Mateos, C. Gómez de Salazar, R. Stoyanova, E. Zhecheva, Carbon 38 (2000) 1031.

[8] Z. Zhu, F. Cheng, Z. Hu, Z. Niu, J. Chen, Highly stable and ultrafast electrode reaction of graphite for sodium ion batteries, J. Power Sources 293 (2015) 626-634.

[9] A. Ponroucha, A.R. Goñia, M.R. Palacín, High capacity hard carbon anodes for sodium ion batteries in additive free electrolyte, Electrochem. Commun. 27 (2013) 85-86.

[10] Y. Li, S. Xu, X. Wu, J. Yu, Y. Wang, Y.-S. Hu, H. Li, L. Chen, X. Huang, Amorphous monodispersed hard carbon micro-spherules derived from biomass as a high performance negative electrode material for sodium-ion batteries, J. Mater. Chem. A 3 (2015) 71-77.

[11] M. Dahbi, T. Nakano, N. Yabuuchi, T. Ishikawa, K. Kubota, M. Fukunishi, S. Shibahara, J.-Y. Son, Y.-T. Cui, H. Oji, S. Komaba, Sodium carboxymethyl cellulose as a potential binder for hard-carbon negative electrodes in sodium-ion batteries, Electrochem. Commun. 44 (2014) 66-69.

[12] G. Schmuelling, T. Placke, R. Kloepsch, O. Fromm, H.-W. Meyer, S. Passerini, M. Winter, X-ray diffraction studies of the electrochemical intercalation of bis(trifluoromethanesulfonyl)imide anions into graphite for dual-ion cells, J. Power Sources 239 (2013) 563-571.

[13] Y. Wang, D. Su, C. Wang, G. Wang, $\mathrm{SnO}_{2} @ M W C N T$ nanocomposite as a high capacity anode material for sodium-ion batteries, Electrochem. Commun. 29 (2013) 8-11.

[14] B. Jache, P. Adelhelm, Use of graphite as a highly reversible electrode with superior cycle life for sodium-ion batteries by making use of co-intercalation phenomena, Angew. Chem. Int. Ed. 53 (2014) 10169-10173.
[15] H. Kim, J. Hong, Y.-U. Park, J. Kim, I. Hwang, K. Kang, Sodium storage behavior in natural graphite using ether-based electrolyte systems, Adv. Funct. Mater. 25 (2015) 534-541.

[16] P. Han, B. Zhang, C. Huang, L. Gu, H. Li, G. Cui, Anticorrosive flexible pyrolytic polyimide graphite film as a cathode current collector in lithium bis(trifluoromethane sulfonyl) imide electrolyte, Electrochem. Commun. 44 (2014) 70-73.

[17] A. Abouimrane, O.C. Compton, K. Amine, S.T. Nguyen, Non-annealed graphene paper as a binder-free anode for lithium-ion batteries, J. Phys. Chem. C 114 (2010) 12800-12804.

[18] K. Du, H. Guo, G. Hu, Z. Peng, Y. Cao, $\mathrm{Na}_{3} \mathrm{~V}_{2}\left(\mathrm{PO}_{4}\right)_{3}$ as cathode material for hybrid lithium ion batteries, J. Power Sources 223 (2013) 284-288.

[19] Z. Jian, L. Zhao, H. Pan, Y.-S. Hu, H. Li, W. Chen, L. Chen, Carbon coated $\mathrm{Na}_{3} \mathrm{~V}_{2}\left(\mathrm{PO}_{4}\right)_{3}$ as novel electrode material for sodium ion batteries, Electrochem. Commun. 14 (2012) 86-89.

[20] J. Maier, Size effects on mass transport and storage in lithium batteries, J. Power Sources 174 (2007) 569-574.

[21] G. Li, D. Jiang, H. Wang, X. Lan, H. Zhong, Y. Jiang, Glucose-assisted synthesis of $\mathrm{Na}_{3} \mathrm{~V}_{2}\left(\mathrm{PO}_{4}\right)_{3} / \mathrm{C}$ composite as an electrode material for high-performance sodiumion batteries, J. Power Sources 265 (2014) 325-334

[22] H. Li, Y. Bai, F. Wu, Y. Li, C. Wu, Budding willow branches shaped $\mathrm{Na}_{3} \mathrm{~V}_{2}\left(\mathrm{PO}_{4}\right)_{3} / \mathrm{C}$ nanofibers synthesized via an electrospinning technique and used as cathode material for sodium ion batteries, J. Power Sources 273 (2015) 784-792.

[23] Y.H. Jung, C.H. Lim, D.K. Kim, Graphene-supported $\mathrm{Na}_{3} \mathrm{~V}_{2}\left(\mathrm{PO}_{4}\right)_{3}$ as a high rate cathode material for sodium-ion batteries, J. Mater. Chem. A 1 (2013) 11350-11354. 